\title{
THE IMPACT OF THE ANIMALS ON CHILDREN'S LEARNING AND THEIR DEVELOPMENT - A STUDY OF WHAT CHILDREN LEARN FROM AND WITH PETS: THE EXAMPLE OF DOG AND CAT
}

\author{
Agneta Simeonsdotter Svensson \\ University of Gothenburg, Sweden \\ E-mail: agneta.simeonsdotter@ped.gu.se
}

\begin{abstract}
The purpose of this study is to produce knowledge about the impact of pets on preschool children's desire to learn and their development. The research question asked is: What do children learn from and with pets: The example of dog and cat? Socio-cultural theories and developmental pedagogy are used in order to study children's learning in the preschool. The socio-cultural theories are based on a model describing interactions between people presented by Vygotskij (1978) and further developed by Säljö (2011). This study employed a qualitative exploratory research method with the aim of gaining knowledge concerning a group of 24 children, aged 4-5 years. Individual interviews were used as the method of data collection. The results are presented as two main categories: 1) The pet supports the child in their learning and development process 2) The child is the teacher of the pet. Each main category comprised two subcategories: 1a) Developing empathy and emotions, 1b) Being good at school-related tasks, 2a) Teaching the pet playful exercises, 2b) Teaching the pet to obey. The results show that pets provide children with positive experiences and a sense of feeling good. The children said that they could talk to all the animals and that the animals are listening. When a child is doing activities with an animal or tries to teach an animal some exercises, the child receives a response from the animal. This leads on to new experiences and an increased knowledge regarding social behavior. Using pets for educational purposes in the home, preschool and school, might stimulate an interest in animal care and a commitment to the world's wildlife and fauna in general.
\end{abstract}

Key words: animal, children, development, preschool learning.

\section{Introduction}

This study aims to promote learning and development in young children. It is based on a collaborative project with an animal protection organization in Sweden (Animal Welfare Sweden, www.djurskyddet.se). International research into relations between humans and animals is mainly about adult's and older people's experiences of life with pets in healthcare and elderly care. The research shows that closeness to animals has good effects on quality of life. Contact with animals produces more positive outlook on life and a meaning in life, which contributes to a better quality of life (McCabe, Braun, Speich \& Agrawal, 2002; Collis \& McNicholas, 2004). In countries such as U.K, France, the USA and Japan, interaction with an animal is a voluntary activity either in the form of having an animal of one's own in institutions or homes or for example, having home visits by health workers together with animal. Such activities are officially supported, but this is not generally the situation in Sweden (Fine, 2000). A positive effect on learning, communication skills, physical health, behavior and emotional well-being characterizes therapy interventions involving animals, regardless of the different characteristics 
Agneta SIMEONSDOTTER SVENSSON. The Impact of the Animals on Children's Learning and Their Development - A Study of What Children Learn From and With Pets: The Example of Dog and Cat

PROBLEMS

OF EDUCATION

IN THE $21^{\text {st }}$ CENTURY

Volume 59, 2014

of the target groups' (Nimer \& Lundahl, 2007). For dog owners the dog itself is often a source of motivation, companionship and social support for physical activity (Cutt, Giles-Corti \& Knuiman 2008a). As regards children, there are many reasons for using animals in educational work. From school research, we know that animals stimulate children's empathy in general and empathy with other people's situations in particular (Daly \& Suggs, 2010). When teachers use animals as a basis for teaching, they find it easier to eater into close collaboration and personal contact with the children; the animals become a shared project and an interest to talk about.

There are many reasons for considering the use of animals in educational work with children. In a study by Tissen, Hergovich \& Spiel (2007) 230 children in grade three in elementary school on ten occasions over ten weeks either received social training and without dogs, or hade a dog present but had no social training. The students showed an improvement in social behavior and empathy in all three programs. In addition, those children showed less who completed the program "social training with dogs" open aggression and aggression towards other people if than the children who followed the other two programs.

Animals often have a decisive impact on a child, sometimes ever be greater than the influence of parents and other people (Melson, 2001). Animals can provide comfort, support, protection, love, friendship and security or act as conductors or intermediaries, based on the child's immediate needs. When animals are an important part of a child's life they contribute development, significant cognitive, emotional and moral processes in the child. Children who have animals around them learn to read the animal's body language and understand what they know and like. Research shows that sharing feelings with an animal can develop empathy, selfconfidence, self-esteem and a belief in their own ability in a child. This is a valuable lesson that children can benefit from in their relationships with humans (Simeonsdotter Svensson, 2013; Melson, 2001).

\section{Problem of Research}

International school studies show that children who have a close relationship with an animal in the home or come into contact with animals in a sympathetic way in school develop greater empathy for both animals and people (Myers, 1998; Poresky, 1990; Vizek-Vidovic et al., 1999). Dadds (2002) noted that a training programme focusing on the child's relationship to animals had an effect on their ability to empathize with both animals and people. Other studies (Tissen, Hergovich \& Spiel, 2007) show that children, who read to a dog, develop speed and an interest in reading and younger children look forward to learning to read. These studies show that contact with animals can lead to better self-esteem, which can lead in turn to better results in school. This study focuses on animals in pre-school children's immediate vicinity, home environment and school. The term animals refer mainly to pets which usually have multiple functions, providing psychological, social and physical stimulation, as well as security and happiness. Most children are interested in animals, making the topic to an appropriate starting point for educational work both in the home environment and in early childhood education. Children relate to the experiences of everyday life, usually the home, which the school may use in pursuing educational activities.

\section{Theoretical Background}

Socio-cultural theories and developmental pedagogy are used in order to study children's learning in the preschool ages. The socio-cultural theories are based on a model describing interactions between people introduced by Vygotskij (1978) and further developed by Säljö (2011). These theories could be applied to a program combining learning with communication and active participation. In socio-cultural theory participation is a social interaction and culturally organized activities play an important role in affecting the psychological means for development (Vygotskij, 1978). A learning / communication situation can be an interaction between 
children and pets. In this study the project sets the frame for communication. The sociocultural perspective integrates the culture of human beliefs of which they are a part; Children are part of

PROBLEMS

OF EDUCATION

IN THE $21^{\text {st }}$ CENTURY

Volume 59, 2014 a social practice, where learning takes place in the interaction between the child and its environment. In this study, children are taught in interactions with pets.

A learning interaction can also be related to a developing pedagogical perspective. Developmental pedagogy emerged from empirical studies where there was a dynamic interplay and close cooperation between children, teachers and researchers (Pramling Samuelsson \& Johansson, 2006; Pramling Samuelsson \& Asplund Carlsson, 2008). Developmental pedagogical theory has its roots in the phenomenographic approach, where the learner's perspective is central. Phenomenography is a qualitatively oriented empirical approach, which was developed at the Department of Education, Gothenburg University (Marton, 1981). Its starting point is an interest in describing phenomena in the world as others see them and uncovering and describing variations in this respect, primarily in a pedagogical context (Marton \&Yan Pong, 2005). In this study younger children's learning and development are related to a learning interaction between children and animals in a given context. The purpose of this study is to produce knowledge about the impact of pets on preschool children's desire to learn and development. What do children learn from and with pets: the example of dog and cat?

\section{Methodology of Research}

Children and animals are easily able to enter into a close and trusting relationships which can have positive effects on child development, including the strengthening of self-esteem, a greater ability to take responsibility and a feeling of better self-control. Animals stimulate presence in the moment and provide love and security without words which can be misunderstood. Animal do not laugh at the children when they do something wrong comfort them instead. They are serving as a listen as best they can. The child always feels important, loved and needed, which builds reinforces and self-confidence. If the child finds social contact with others difficult, animals can be an easier option for a relationship. Children do not always feel that they want to open up to adults and make use of them because they may feel that it is precisely those adults who have failed them in various situations (Tissen, Hergovich \& Spiel, 2007). This study presents a group of children at a preschool who wants to talk about pets and share their thoughts. A sociocultural perspective on the relationship, child- pet is a starting point. It is in the interaction between children and pets as learning occurs.

\section{Sample of Research}

The study involved 24 children from the metropolitan region of Gothenburg, 12 boys and 12 girls. A preschool near the University of Gothenburg was contacted via mail. The teachers were interested participating in a study conducted at their preschool. Ethical considerations were dealt with at an early stage in the contact with children and their families. The children and their families were informed that they could withdraw their participation at any time and that confidentiality was guaranteed. Thus, all those who participants in the study remain anonymous and have been assigned fictitious names (Research Council, 2007).

\section{Instruments and Procedures}

A qualitative research method was used in this study, with the aim of gaining knowledge about a group of preschool children aged 4-5 years. Interviews, with an emphasis on conversation, were used as a method of data collection and a socio-cultural perspective was applied to the material (Vygotskij, 1978; Säljö, 2011). In all pedagogical approaches interviewing children the children's own perspectives and expressions becomes important to take into consideration 
Agneta SIMEONSDOTTER SVENSSON. The Impact of the Animals on Children's Learning and Their Development - A Study of What Children Learn From and With Pets: The Example of Dog and Cat

PROBLEMS

OF EDUCATION

IN THE $21^{\text {st }}$ CENTURY Volume 59, 2014

80

(Sommer, Pramling Samuelsson \& Hundeide, 2010, 2013). The interviews lasted from 3060 minutes and were conducted by the author into the role of researcher. The children were interviewed one by one at the preschool. The interviews were recorded and later transcribed verbatim. Introductory questions were asked about whether the children had pets at home, if they had pets before or perhaps wanted a pet. The talks that followed included questions about what the pets did for children and what they usually did together with the animal. Other questions were whether the children were able to learn anything about the pets and whether the pets could teach them anything, and if so, what. Various communication patterns were identified and related to the purpose of the study and the issues. During the interviews revealed that all 24 children have or had had the dog or cat. Seven of the children have or had also had other animals. These animals were bird, hamster, fish and rat. Dog and cat was mentioned, however, when the children told me what they learn from and with pets. Therefore, in the selection of interviews, pets are represented by dog or cat in the citations of the children.

\section{Analysis of Data}

The qualitative acceptability of the method was investigated by analyzing the conversations between the children and the researcher and their talk about pets. The recording conversations relevant content and learning was investigated the recorded conversation. Measurable items and patterns were identified, with reference is learning associated with animals. The method chosen for the analysis was phenomenography (Marton \& Pong, 2005). The transcribed text from the conversations was read carefully by the author. The interpretation from the entirety to the parts was conducted in order to increase understanding of the text. The interpretation process in a phenomenographic analysis can be seen as a chain of interpretations based on the whole and the parts and the whole (Marton, Beaty \& Dall'Alba, 1993; Marton \& Pong, 2005). Interpretation of the whole and the parts is linked mostly by hermeneutics and the hermeneutic spiral (Gadamer, 1999). Part and whole must be related to each other in a reasonable manner in order to be credible, which is how phenomenographic inspired analysis is used in this study. Interpretation and understanding of the process involves an understanding of the context; understanding or the whole increases, which also changes the understanding of the individual parts.

Throughout the process, the parts of the text were first analyzed independently by the author and then to increase the trustworthiness of the analysis, the categories were checked for content. The children's statements were identified and categorized. The entirety and the parts come together and the dependency between them was seen to answer the aim of the study. Categories were created for the outcomes describing the responder's different ways of apprehending/experiencing the phenomenon. Similarities in understanding constituted one category. According to the method the criteria for the categories were: being related to the phenomenon; the presence of a logical relation among the categories; as few categories as possible to cover the critical variations in the data (Marton \& Pong, 2005). Representative quotes of statements by the children supported the meaning of the categories and increased trustworthiness of the analysis.

\section{Results of Research}

The purpose of this study is to produce knowledge about the impact of pets on preschool children's desire to learn and development. What do children learn from and with pets: example dog and cat?

The results produce two main categories: 1) Pets support the child in the learning and development process 2) The child is the teacher of the pet. Each main category consisted of two subcategories: 1a) Developing empathy and emotions, 1b) Being good at school-related tasks, 2a) Teaching the pet playful exercises, 2b) Teaching the pet to obey. The pets represented 
in the study are dogs and cats. The quotations below are examples showing how pets support the child in the learning and development process as well as how the child is the teacher of the

pet: the example of dog and cat. This can be done in a variety of ways, but should start from the children's interest in a learning situation (Marton \& Pong, 2005; Pramling Samuelsson \& Johansson, 2006; Pramling Samuelsson \& Asplund Carlsson, 2008).

1) Pets support the child in the learning and development process

\section{1a) Developing empathy and emotions}

The category describes how animals help to develop children's empathy and emotions. The children put into words the emotions they feel in relation to the pet. Support in this category concerns emotional support which, in turn, is important for learning and development. Four children: Peter, Anna, Birgitta and Johan represent this category.

1. My dog will come and cuddle with me in bed every night. He is so nice. I'll give him candy. He likes it and I do too. I feel a little better, when I do that (Peter).

2. Kirre (cat) settles on my lap and purrs. I will be happy then. I feel it all through my body (Anna).

3. Have held her (dog) in my arms. She wants me to carry her. She jumps on me and wants to get up. Then she won't hurt her feet if I carry her. She kisses me all the time and then I feel calm (Birgitta).

4. Misse (cat) is so funny! He lies on my stomach when I am asleep and is so cute. I love him. I fall asleep, then (Johan).

In the first sub-category, developing empathy and emotions the animal is for the children. The dog or cat comes to them and wants to cuddle which is perceived as positive and fun. They think it feels good to cuddle a pet. The children express how much they like the animal and feel for the animal. Empathy and learning go hand in hand for the kids. They learn to develop empathy and to put words to feelings, which is part of the development process. According to Vygotskij (1978) all can develop in any way. It is therefore important that adults see children's potentials in order to serve as the mainstay for them in their development and learning process.

\section{1b) Being good at school-related tasks}

This category highlights children's reflections on that their ability to become skilled at learning school-related tasks. The school-related tasks that children describe are drawing, painting or reading and counting. They may have received information from the teacher at the preschool that they will then use at home or they play school at home and want to try writing and arithmetic. Carl, Susanne, Roger and Boris represent this category.

1. Do you know, I have learned to read? Did it all by myself. Read to Blixten (dog) the story of the Little Uncle. He was really happy when I read. Probably thought it was funny (Carl).

2. I read a bedtime story to my cat, Lisa. She can listen, but she says nothing, just Meow and that is probably good, I think (Susanne).

3. My cat can paint with his tail and then I show her how to do it, with a bit of paint on the paper. Then I do her a nice drawing. It looks like she wants me to (Roger)!

4. Teacher said we could borrow books. I borrowed a book about dogs that I showed to my dog. I had the same picture as on my book. He was happy and barked when he saw it. Then I showed him all the pictures (Boris). 
Agneta SIMEONSDOTTER SVENSSON. The Impact of the Animals on Children's Learning and Their Development - A Study of What Children Learn From and With Pets: The Example of Dog and Cat

PROBLEMS

OF EDUCATION

IN THE $21^{\text {st }}$ CENTURY Volume 59, 2014

The second sub-category being good at school-related tasks show the children experiencing that the animal listens without judging what is right or wrong. Both the dog and the cat support them, the children. Thing it is safe when the pet listens when they read the story or draw and paint. The children experience genuine pleasure, and have a feeling that the animal is also experiencing joy, a shared joy. Feeling that an animal is listening only you to and giving you their full attention, gives children a satisfaction and a desire to learn more.

2) The child is the teacher of the pet

\section{2a) Teaching pet playful exercises}

This category covers children teaching the pet playful exercises, to their mutual involving common joy. Exercises the children talk about are jumping over obstacles, crawling in the "tunnel", agility exercises (dog), playing with a small ball of string and teaching the animal to catch it, balancing on a railing and "sneaking nicely" (cat). The children are: Anette, Patrick, Christina and Jonna.

1. Guess, I have taught my dog a lot of fun things. I taught him to go into the tunnel. He's good; I've taught him all summer. First, we practiced at slowly, then running fast (Anette).

2. Oh, what fun we have. Lillan (cat) can chase the mouse now. But it is not a real mouse; it is a toy mouse, for cats. I've trained her. Now she does it, you see! But I had to show her lots of times what to (Patrick).

3. My dog has learned to jump over the crossbar. It is high, the crossbar. He could not do it at first, but then I showed him, and then he was great. It is fun (Christina).

4. I have two cats and they are mischievous. And I found funny things to them to do at home. They may not go out by themselves. I usually show how to climb a tree for cats that we have at home (Jonna).

The playful exercises create a common activity for the children and animals to do together. Both children and animals enjoy the activity and develop by working at it. The exercises are led by the child who feel that they are teaches the animal what to learn. The child acts as a teacher and the pet as a pupil. Being the teacher helps to strengthen self-confidence of the child. When children are involved in pleasurable activities with pets, they grow with the task and their imagination develops.

\section{2b) Teaching the pet to obey}

Children think it is important for dogs and cats to be obedient. The child wants the animal to obey in a special situation. It such as coming on command, sitting on command, walking nicely, lying still and quiet. Learning to obey is different from having "fun sessions", it is serious, not playing. Sara, Tor, Matilda and Sally represent this category.

1. Worked with my dog, you know. Have taught him to obey. I have taught him to sit nicely. Just me, not mom or dad and I am very strict (Sara).

2. My Alva (cat) is not very good at obeying and a bit bothersome; doesn't do as I say a little weird and silly. When I say "sleep" I want her to be still so we can cuddle (Tor).

3. Sarah (dog) is good. She runs away from me out there and I call her "come, come, come,"and she comes to me. She obeys me because we practice it a lot (Matilda).

4. I try to teach my cat to lie still. It is a bit hard to teach her. I have trick that Anita (sister) cannot do. I say "boo" and he lies down. But then he sneaks out again almost immediately. Mom says you can't teach a cat to obey but I want to so I can caress her (Sally). 
The children see it as an important task to teach the pet obey. Dogs are perceived as be-

PROBLEMS

OF EDUCATION

IN THE $21^{\text {st }}$ CENTURY

Volume 59, 2014 ing easier to teach obedience while cats are thought to be more difficult. In this subcategory the children express the idea that there is a difference between dogs and cats regarding obedience. Children who have a cat believe that cats do not obey like dogs. They are convinced, however, that cats should obey so that they can be cuddled.

\section{Discussion}

\section{Learning From and With Pets}

The purpose of this study was to produce knowledge about the impact of pets on preschool children's desire to learn and their development. Interviewing young children requires not only knowledge about how children think and speak and use body language according, to age but also the skill to pick up and interpret what the child is trying to express (Sommer, Pramling Samuelsson \& Hundeide, 2010). It is actually more difficult to interview young children than adults. Younger children usually use body language when they communicate, which complements and clarifies their spoken language. What do children learn from and with pets? The answer can formulate in two main categories: 1) a pet supports the child in the learning and development process 2) the child is the teacher of the pet. Each main category comprises two subcategories: 1a) developing empathy and emotions; 1b) being good at school-related tasks; $2 \mathrm{a})$ teaching the pet playful exercises; $2 b)$ teaching the pet to obey. Nine girls and seven boys represent the categories. The 16 children talking about the pets in ways that categories shows. Not any category more represented. No category is distinguished from the other. The eight children who are not examples ( 8 of 24 ) varied across categories. No overweight there either.

The study shows that pets, example dog and cat, contribute to children's learning and development in several ways. They support the child in the learning and development process by helping them to develop the empathic ability and making the child feel with the animal. It is fun to play with the pet and to learn from and with it, especially dog and cat. Maybe the dogs and cats are more accessible than rodents and birds. They are seen as someone to "cuddle" and enjoy. Pets in general and dogs and cats in particular, give children positive experiences and a sense of feeling good. They create a relationship with the animal, feel safe with it. This later leads to their creating relationships with other people; through sharing a common interest, for example communication between children and adults develops as Daly \& Suggs (2010) also point out in their a study.

The relationship between animals and people has special qualities that distinguish it from human relations. It is based on a non-verbal communicating between two beings who do not share a language other than through movement and touch. In contact with animals given the children opportunities to communicate their thoughts in words. The speech and language of preschool children are stimulated and develops in interaction with the animal. The urge to use speech and language is stimulated when the child reads or tells a story to the animal. The child may then feel they are good at school-related tasks. The children are more inspirited to absorb knowledge and the knowledge becomes more lasting through concrete experiences. In this study, we see the children's spontaneous joy and happiness when they communicate with animals. As the child reads, narrates or any other activity with the animal, the animal is there as a good listener. When the child tries to teach the animal exercises or reads to it, the child receives the response from the animal, this leads to new experiences and an increase of knowledge regarding social behavior (cf. Tissen, et al., 2007). 
Agneta SIMEONSDOTTER SVENSSON. The Impact of the Animals on Children's Learning and Their Development - A Study of What Children Learn From and With Pets: The Example of Dog and Cat

\author{
PROBLEMS \\ OF EDUCATION \\ IN THE $21^{\text {st }}$ CENTURY \\ Volume 59, 2014 \\ 84 Conclusions
}

Animals are important to children. They possess many qualities and contribute to the child's learning and development. Using pets for educational purposes in homes, preschools and schools may arouse an interest in animal care and commitment to the natural world and its fauna. It's way also forms the basis for the choice of training for interested children and young people, expressed as the "use of animals for training purposes." Sweden and many other countries, however, animals are not present in preschools and schools. One reason cited for this is that many children are allergic, especially to dogs and cats. Studying the impact of the preschool children's desire to learn and their development, and what children learn from and with pets, is opposed if live animals are to be present. Alternative types of schools where animals play a natural part in the education may be one way to go. When animals become the basis of conversations between children and adults makes close collaboration and personal contact with the children easier, the animals become a shared project and interest to be talked about. It creates empathy, which means helpfulness, caring and a sense of responsibility. It also encourages an ethical attitude towards people, animals and nature. It might be interesting to follow the children in a larger longitudinal study and examine the effects of using animals for learning and development purposes. Studies based on a quantitative methodology may be appropriate for comparing approaches in different countries

\title{
Acknowledgments
}

The author thanks Richard Ingemannsen for valuable technical support. Also, thanks children and teachers who participated.

\section{References}

Collis, G. M., \& McNicholas, J. (2004). Pets and the health of older people. Department of psychology, University of Warwick.

Cutt, H., Giles-Corti, B., \& Knuiman, M. (2008a). Encouraging physical activity through dog working: Why don't some owner's worker walk with their dog? Preventive Medicine, 46, 120-126.

Dadds, M. R. (2002). Developmental links between cruelty to animals and human violence. The Australian and New Zealand Journal of Criminology, 35 (3), 363-382.

Daly, B., \& Suggs, S. (2010). Teacher's experiences with humane education and animals in the elementary classroom: implications for empathy development. Journal of Moral Education, 39 (1), 101112.

Djurskyddet Sverige (Animal Welfare Sweden) (2012). Retrieved from http://www.djurskyddet.se

Fine, A. Ed. (2000). Handbook on animal assisted therapy. Academic Press.

Gadamer, H. G. (1999). Hermeneutics, religion, and ethics. New Haven, CT: Yale University Press.

Marton, F. (1981). Phenomenography - describing conceptions of the world around us. Amsterdam: Elsevier Scientific publishing Company.

Marton, F., \& Pong, W Y. (2005). On the unit of description in phenomenography. Higher Education Research \& Development, 24 (4), 335-348. DOI: 10.1080/07294360500284706.

Marton, F., Beaty, E., \& Dall'Alba, G. (1993). Conceptions of learning. International Journal of Educational Research, 19 (3), 277-300.

McCabe, B. W., Braun, M. M., Spiech., D., \& Agrawal, S. (2002). Resident dog in the Alzheimer's special care unit. Western Journal of Nursing Research, 54-65.

Melson, G. F. (2001). Why the wild things are: animals in the lives of children. Harvard University Press, Cambridge, Massachusetts, London.

Myers, G. (1998). Children and animals: Social development and our connections to other species. Boulder, CO: Westview Press.

Nimer, J., \& Lundahl, B. (2007). Animal-assisted therapy: A meta-analysis. Anthrozoos, 20 (5), 225238. 
Poresky, R. H. (1990). The young children's empathy measure: Reliability, validity and effects of companion animal bonding. Psychological Reports, 66 (3), 931-936. doi: 10.2466/pr0.1990.66.3.931.

Pramling Samuelsson, I., \& Asplund Carlsson, M. (2008). The playing learning child: Towards pedagogy of early childhood. Scandinavian Journal of Educational Research, 52 (6), 623-641.

Pramling Samuelsson, I., \& Johansson, E. (2006). Play and learning - inseparable dimensions in preschool practice. Early Child Development and Care, 176 (1), 47-65.

Research Council (2007). Research Ethical principles in human science research. Retrieved April 4, 2013, from http://www.vr.se

Simeonsdotter Svensson, A. (2013). Pre-school children development empathy through individualized materials. Problems of Education in the 21st Century, 52, 115-124.

Sommer, D., Pramling Samuelsson, I., \& Hundeide, K. (2010). Child perspectives and children's perspectives in theory and practice. New York: Springer.

Sommer, D., Pramling Samuelsson, I., \& Hundeide, K. (2013). Early childhood care and education - a child perspective paradigm. European Early Childhood Education Research Journal, 21 (4), 459475.

Säljö, R. (2011). Learning in a sociocultural perspective. V. Grover Aukrust Learning and Cognition in Education, 59-63.

Tissen, I., Hergovich, A., \& Spiel, C. (2007). School-based social training with and without dogs: Evaluation of their effectiveness. Antrozoos, 20 (3), 365-373.

Vizek-Vidovic, V., Stetic, V. V., \& Bratko, D. (1999). Pet ownership, type of pet and socioemotional development of school children. Anthrozoos, 12 (4), 211-217.

Vygotskij, L. S. (1978). Mind of Society: The development of higher psychological processes. In V. Cole, S. John-Steiner, E. Scribner \& E. Sauberman (Eds). Cambridge, Ma: Harvard, University Press.

Advised by Anita Franke, University of Gothenburg, Sweden

Received: January 29, 2014

Accepted: March 28, 2014

Agneta Simeonsdotter Svensson
$\mathrm{PhD}$, Senior Lecturer, Department of Education, Communication and Learning, University of Gothenburg, Box 300, 405 30, Gothenburg, Sweden.

E-mail: Agneta.simeonsdotter@ped.gu.se

Website: http://www.ipkl.gu.se/om-ipkl/personal
PROBLEMS

OF EDUCATION

IN THE $21^{\text {st }}$ CENTURY

Volume 59, 2014

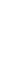

